\title{
Effect of Al Hot-Dipping on High-Temperature Corrosion of Carbon Steel in $\mathrm{N}_{2} / 0.1 \% \mathrm{H}_{2} \mathrm{~S}$ Gas
}

\author{
Muhammad Ali Abro and Dong Bok Lee* \\ School of Advanced Materials Science and Engineering, Sungkyunkwan University, Suwon 16419, Korea; \\ muhammad_aliabro@inbox.com \\ * Correspondence: dlee@skku.ac.kr; Tel.: +82-31-290-7355; Fax: +82-31-290-7371
}

Academic Editors: Vineet V. Joshi and Alan Meier

Received: 11 January 2016; Accepted: 5 February 2016; Published: 17 February 2016

\begin{abstract}
High-temperature corrosion of carbon steel in $\mathrm{N}_{2} / 0.1 \% \mathrm{H}_{2} \mathrm{~S}$ mixed gas at $600-800{ }^{\circ} \mathrm{C}$ for 50-100 h was studied after hot-dipping in the aluminum molten bath. Hot-dipping resulted in the formation of the Al topcoat and the Al-Fe alloy layer firmly adhered on the substrate. The Al-Fe alloy layer consisted primarily of a wide, tongue-like $\mathrm{Al}_{5} \mathrm{Fe}_{2}$ layer and narrow $\mathrm{Al}_{3} \mathrm{Fe}$ layer. When corroded at $800{ }^{\circ} \mathrm{C}$ for $100 \mathrm{~h}$, the $\mathrm{Al}$ topcoat partially oxidized to the protective but non-adherent $\alpha-\mathrm{Al}_{2} \mathrm{O}_{3}$ layer, and the interdiffusion converted the $\mathrm{Al}$-Fe alloy layer to an $\left(\mathrm{Al}_{13} \mathrm{Fe}_{4}, \mathrm{AlFe}_{3}\right)$-mixed layer. The interdiffusion also lowered the microhardness of the hot-dipped steel. The $\alpha-\mathrm{Al}_{2} \mathrm{O}_{3}$ layer formed on the hot-dipped steel protected the carbon steel against corrosion. Without the Al hot-dipping, the carbon steel failed by forming a thick, fragile, and non-protective FeS scale.
\end{abstract}

Keywords: $\mathrm{H}_{2} \mathrm{~S}$ corrosion; hot-dip aluminizing; carbon steel; microhardness

\section{Introduction}

The $\mathrm{H}_{2} \mathrm{~S}$ gas comes off as a by-product during processing in oil refineries, petrochemical plants and fossil-fired power plants. It dissociates into sulfur and hydrogen, and embrittles and corrodes the steel seriously by forming FeS scales incorporated with some hydrogen to dangerously shorten the service life of the steel. FeS is entirely non-protective, and grows fast owing to its high non-stoichiometry and low melting point [1]. Hydrogen released from the $\mathrm{H}_{2} \mathrm{~S}$ gas ingresses in the scale and steel interstitially as molecular hydrogen $(\mathrm{H})$, generates lattice point defects, forms hydrogen clusters, and thereby increases the corrosion rate greatly. Since steels cannot resist the $\mathrm{H}_{2} \mathrm{~S}$ corrosion at high temperatures, they need to be coated. Al hot-dipping is an effective, inexpensive and simple anti-corrosion coating technique for steels [2]. The hot-dipped coating consists of the Al-rich topcoat and the inner Al-Fe alloy layer that is composed of an outer minor $\mathrm{Al}_{3} \mathrm{Fe}$ layer (near topcoat side) and an inner major $\mathrm{Al}_{5} \mathrm{Fe}_{2}$ layer (near steel substrate side). An irregular tongue- or finger-like morphology develops between the inner major $\mathrm{Al}_{5} \mathrm{Fe}_{2}$ layer and the steel substrate [3,4]. The Al hot-dipping drastically improved the oxidation resistance of steels by forming the highly protective $\alpha-\mathrm{Al}_{2} \mathrm{O}_{3}$ layer upon exposure to air at high temperatures [5-7]. However, the corrosion resistance of Al-coated carbon steels in the $\mathrm{H}_{2} \mathrm{~S}$-containing gas was not yet adequately studied. The purpose of this study was to investigate the corrosion behavior of the Al hot-dipped carbon steel under $\mathrm{N}_{2} / 0.1 \% \mathrm{H}_{2} \mathrm{~S}$ mixed gas at high temperatures in order to utilize the $\mathrm{Al}$ hot-dipped steel in the hostile $\mathrm{H}_{2} \mathrm{~S}$-containing environments.

\section{Experimental Procedure}

A medium carbon steel plate with a nominal composition of Fe-0.44 C-0.30 Mn-0.25 Si-0.019 S-0.016 P (wt. \%) was cut to $80 \times 20 \times 2 \mathrm{~mm}^{3}$ size coupons, ground using SiC sand paper No. 1200, 
cleaned ultrasonically in alcohol, subjected to the liquid flux solution consisting of 20 vol. $\% \mathrm{KCl}$ and $\mathrm{AlF}_{3}$ in 4:1 weight ratio in water. After drying, the coupons were immersed in the pure molten $\mathrm{Al}$ bath on top of which a solid flux $\left(\mathrm{KCl}+\mathrm{NaCl}+\mathrm{AlF}_{3}\right.$ in 2:2:1 in weight ratio) was spread to protect the molten $\mathrm{Al}$ bath from oxidation. The $\mathrm{Al}$ hot-dipped steel was pulled out, cooled to room temperature in air, further cleaned using $5 \mathrm{vol} . \% \mathrm{HNO}_{3}$ solution to remove any flux adhered on the aluminized surface, placed in a quartz tube furnace and exposed at $600-800{ }^{\circ} \mathrm{C}$ for up to $100 \mathrm{~h}$ in $\mathrm{N}_{2} / 0.1 \% \mathrm{H}_{2} \mathrm{~S}$-mixed gas. After the corrosion tests the Al hot-dipped steel specimens were examined by an optical microscope (OM; Leica DM2700, Leica Microsystems, Switzerland), a scanning electron microscope (SEM, Hitachi S3000-N, Tokyo, Japan) equipped with an energy dispersive spectroscope (EDS; Horiba Ex-220, Kyoto, Japan) and a high power X-ray diffractometer (XRD; Bruker D8 Advance, Karlsruhe, Germany) using $\mathrm{Cu}-\mathrm{K} \alpha$ radiation operating at $40 \mathrm{kV}$ and $300 \mathrm{~mA}$. Before analyzing the results using above microstructural techniques, the cross-sections were etched in a reagent consisting of $5 \%$ nitric acid, $5 \%$ sulfuric acid, and $0.1 \%$ hydrofluoric acid. The Vickers microhardness (Microhardness Tester, Mitutoyo MVK-H2, Kanagawa, Japan) of the Al hot-dipped steel specimen was measured along the coating depth at room temperature under an indentation load of $100 \mathrm{~g}$ for $5 \mathrm{~s}$, with an average indentation interval of $50 \mu \mathrm{m}$.

\section{Results and Discussion}

Figure 1 shows OM/EDS/XRD results of the Al hot-dipped carbon steel. Figure 1a indicates that the hot-dipped coating consists of the Al topcoat with a thickness of about 50-60 $\mu \mathrm{m}$ and the Al-Fe alloy layer with a thickness of 170-230 $\mu \mathrm{m}$. The characteristic finger- or tongue-like morphology was seen between the Al-Fe alloy layer with the columnar microstructure and the steel substrate having equiaxed grains [8]. It originated from the fast inward diffusion of $\mathrm{Al}$ during hot-dipping through the orthorhombic $\mathrm{Al}_{5} \mathrm{Fe}_{2}$ with $30 \%$ vacancies along the $c$-axis [4], or from the atomic size mismatch between $\mathrm{Al}$ (atomic radius; $0.143 \mathrm{~nm}$ ) and $\mathrm{Fe}$ (atomic radius; $0.126 \mathrm{~nm}$ ) [9]. Figure $1 \mathrm{~b}$ indicates the EDS concentration spot analysis (at. \%). Spots 1-4, 5-19 and 20-22 corresponded to the Al topcoat, Al-Fe alloy layer, and the steel substrate, respectively. The $\mathrm{Al} / \mathrm{Fe}$ compositional ratios (at. \%) at spots 5-6 and 7-19 were 2.9 and 2.6, respectively, suggesting that mainly $\mathrm{Al}_{3} \mathrm{Fe}$ and $\mathrm{Al}_{5} \mathrm{Fe}_{2}$ were formed in the alloy layer between the topcoat and the substrate. SEM/EDS analysis indicated that no aluminum was detected below spot 19. The alloying elements such as $\mathrm{Mn}$ and $\mathrm{Si}$ were detected in a small amount inside the coating (Figure 1b), implying their dissolution in the coating. The intensity of diffraction patterns decreased in the order of $\mathrm{Al}, \mathrm{Al}_{5} \mathrm{Fe}_{2}$, and $\mathrm{Al}_{3} \mathrm{Fe}$ in Figure $1 \mathrm{c}$, and decreased in the order of $\mathrm{Al}_{5} \mathrm{Fe}_{2}$ and $\mathrm{Al}_{3} \mathrm{Fe}$ in Figure 1d. This indicated that the Al-Fe alloy layer that existed below the $\mathrm{Al}$ topcoat was composed of $\mathrm{Al}_{5} \mathrm{Fe}_{2}$ as the major phase, and $\mathrm{Al}_{3} \mathrm{Fe}$ as the minor one $[3,4]$.
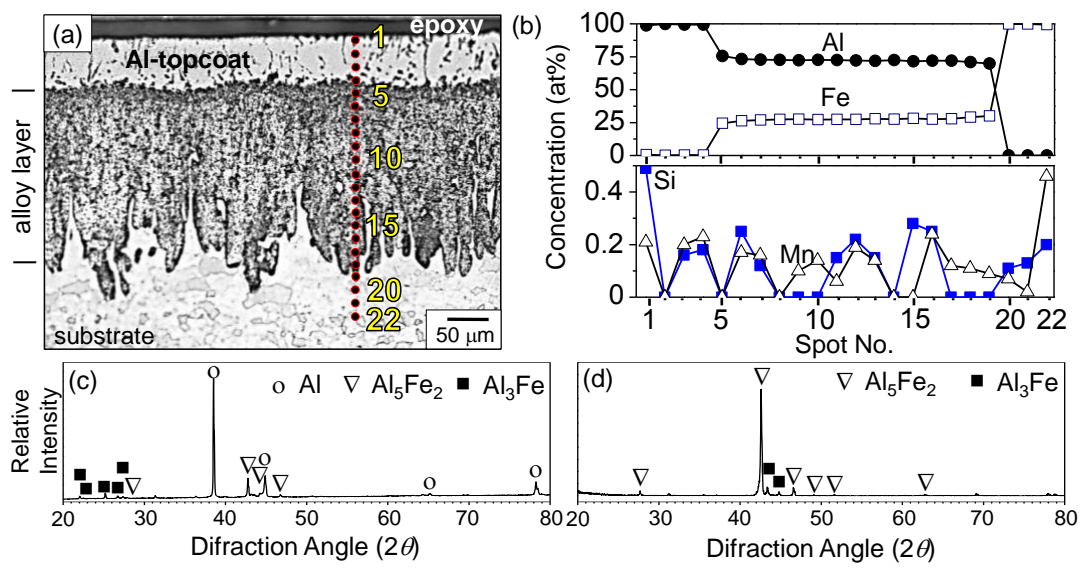

Figure 1. Al hot-dipped carbon steel: (a) Etched cross-sectional OM image; (b) EDS concentration profiles along the spots 1-22 marked in Figure 1a; (c) XRD pattern taken from the air-side; (d) XRD pattern after grinding off the $\mathrm{Al}$ topcoat. 
Figure 2 shows XRD/OM results of the $\mathrm{Al}$ hot-dipped carbon steel after corrosion at $600{ }^{\circ} \mathrm{C}$ for 50 h. In Figure $2 \mathrm{a}, \alpha-\mathrm{Al}_{2} \mathrm{O}_{3}$ and $\mathrm{Al}_{5} \mathrm{Fe}_{2}$ were detected as the minor and major phases, respectively. The $\mathrm{Al}$ topcoat partially oxidized to $\alpha-\mathrm{Al}_{2} \mathrm{O}_{3}$, and leftover (i.e., uncorroded) aluminum topcoat along with the underlying $\mathrm{Al}_{3} \mathrm{Fe}$ layer transformed to the $\mathrm{Al}_{5} \mathrm{Fe}_{2}$ not only due to the outward diffusion of $\mathrm{Fe}$ (from the substrate to the surface) but also due to the inward diffusion of $\mathrm{Al}$ (from the coating towards the interior) during heating under $\mathrm{N}_{2} / 0.1 \% \mathrm{H}_{2} \mathrm{~S}$ gas. The oxygen source for the formation of $\alpha-\mathrm{Al}_{2} \mathrm{O}_{3}$ was the impurity of oxygen in the $\mathrm{N}_{2} / 0.1 \% \mathrm{H}_{2} \mathrm{~S}$ gas. The $\alpha-\mathrm{Al}_{2} \mathrm{O}_{3}$ scale with a thickness of about $5 \mu \mathrm{m}$, the underlying $\mathrm{Al}_{5} \mathrm{Fe}_{2}$-rich alloy layer, and the substrate were shown in Figure $2 \mathrm{~b}$. The $\alpha-\mathrm{Al}_{2} \mathrm{O}_{3} \mathrm{scale}$ was non-adherent due to the incorporation of sulfur and hydrogen from $\mathrm{H}_{2} \mathrm{~S}$ and the mismatch of thermal expansion coefficients between the scale and the alloy layer.
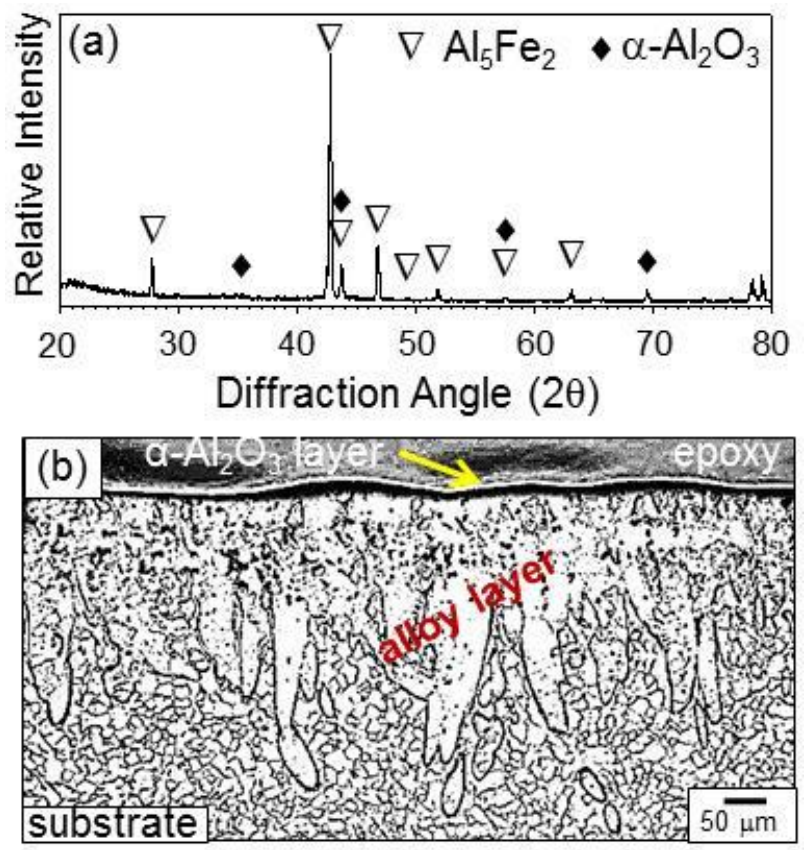

Figure 2. Al hot-dipped carbon steel after corrosion at $600{ }^{\circ} \mathrm{C}$ for $50 \mathrm{~h}$ in $\mathrm{N}_{2} / 0.1 \% \mathrm{H}_{2} \mathrm{~S}$ gas: (a) XRD pattern; (b) etched cross-sectional OM image.

Without aluminum hot-dipping, the carbon steel was corroded seriously, as shown in Figure 3. The corrosion condition selected for the uncoated steel was the same as described in Figure 2 (i.e., $600{ }^{\circ} \mathrm{C}$ for $50 \mathrm{~h}$ ) in order to find the effect of hot-dip aluminizing. The scale formed on the uncoated steel was $\sim 165-200 \mu \mathrm{m}$ thick (Figure 3a), and consisted of FeS (Figure 3b). The scale was fragile and easily detached from the matrix owing to the incorporation of sulfur and hydrogen from $\mathrm{H}_{2} \mathrm{~S}$. Moreover, excessively large growth stress had arisen due to the formation of a thick scale, and the thermal stresses generated during corrosion and the subsequent cooling stage. Since FeS has a defect structure of $\mathrm{Fe}_{1-x} \mathrm{~S}(x=0-0.2)$, it grows rapidly through the outward diffusion of $\mathrm{Fe}^{2+}$ ions, leaving Kirkendall voids behind [1]. Hence, numerous voids formed at the bottom of the FeS scale, which could act as stress concentration sites to facilitate the scale spallation (Figure 3a). 

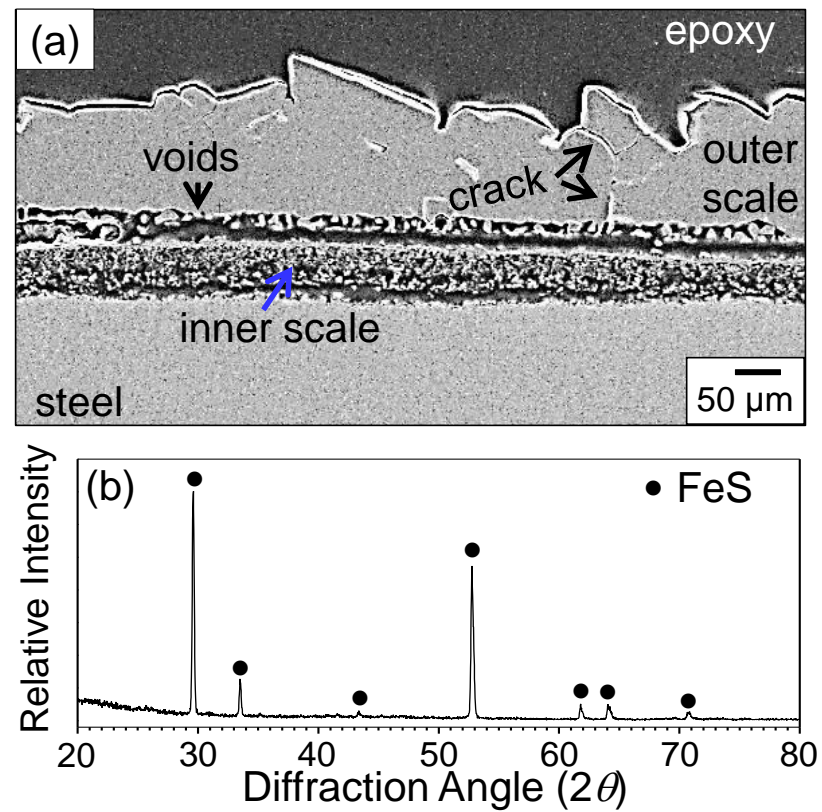

Figure 3. Uncoated steel after corrosion in $\mathrm{N}_{2} / 0.1 \% \mathrm{H}_{2} \mathrm{~S}$ at $600{ }^{\circ} \mathrm{C}$ for $50 \mathrm{~h}$ : (a) SEM cross-sectional image; (b) XRD pattern.

Figure 4 shows SEM/EDS/XRD results of the Al hot-dipped carbon steel after corrosion at $800{ }^{\circ} \mathrm{C}$ for $100 \mathrm{~h}$. In Figure $4 \mathrm{a}$, the $\alpha-\mathrm{Al}_{2} \mathrm{O}_{3}$ scale was about $5 \mu \mathrm{m}$ thick, non-adherent, and partially broken owing to the excessive stress accumulated in the scale as well as the hydrogen and sulfur released from the $\mathrm{H}_{2} \mathrm{~S}$ gas. According to the SEM-EDS analysis, the composition of spot 1 shown in Figure $4 \mathrm{~b}$ was $38.9 \% \mathrm{Al}-58.1 \% \mathrm{O}-2.8 \% \mathrm{~S}-0.2 \% \mathrm{Fe}$ in wt. $\%$, which indicated that $\alpha-\mathrm{Al}_{2} \mathrm{O}_{3}$ was incorporated with some sulfur and iron. Such was also observed at the spot 2 shown in Figure $4 \mathrm{~b}$. Sulfur and iron ions that were doped in the highly stoichiometric $\alpha-\mathrm{Al}_{2} \mathrm{O}_{3}$ may constitute additional energy levels localized in the forbidden energy band, which would beneficially increase the defect mobility in $\alpha-\mathrm{Al}_{2} \mathrm{O}_{3}$ and thereby enhance the formation of $\alpha-\mathrm{Al}_{2} \mathrm{O}_{3}$. Sulfur was present only at spot $1(2.8 \mathrm{wt}$. \%) and spot 2 (1.6 wt. \%). However, oxygen was present all over spots 1-25, with its concentration (wt. \%) gradually decreased from $58.1 \% \mathrm{O}$ at spot 1 to $0.6 \% \mathrm{O}$ at spot 25 . This suggested that oxygen diffused inwardly faster and more in-depth than sulfur. Nevertheless, the thin $\alpha-\mathrm{Al}_{2} \mathrm{O}_{3}$ scale effectively protected the steel, suppressing the formation of the non-protective $\mathrm{FeS}$ or less protective $\mathrm{Al}_{2} \mathrm{~S}_{3}$ scale at the coating surface. In Figure 4a, spots 1-15 were not able to be etched due to the dissolution of oxygen and sulfur to a certain amount, while spots 15-25 were able to be etched, which revealed coarse, fully grown substrate grains. Hence, the boundary between the retained coating and the substrate may be designated as spot 15 . Numerous voids formed at spots $12-16$, and furthermore, at spots $2-4$ due to the interdiffusion between the coating and the substrate. The amount of void formation increased with an increase in the corrosion temperature and time. A few cracks formed due to thermal expansion mismatch between coating and the steel substrate [6]. Because of the counter-diffusion of $\mathrm{Al}$ and $\mathrm{Fe}$, the characteristic finger- or tongue-like morphology as shown in Figure 1a was no longer observable in Figure 4a. In Figure 4c, the strongest peaks were in the order of $\mathrm{Al}_{13} \mathrm{Fe}_{4}$ and $\mathrm{AlFe}_{3}$, indicating that the upper part of the retained coating (viz around spot 3 in Figure 4a) consisted of $\mathrm{Al}_{13} \mathrm{Fe}_{4}$ as the major phase and $\mathrm{AlFe}_{3}$ as the minor phase. Additionally, faint peaks of $\alpha-\mathrm{Al}_{2} \mathrm{O}_{3}$ and $\mathrm{FeS}$ were detected in Figure 4c. A small amount of FeS was formed at the coating surface not only because of the $\alpha-\mathrm{Al}_{2} \mathrm{O}_{3}$ scale spallation but also due to the preferential oxidation of $\mathrm{Al}$ at the outer surface. When the upper part of the coating was ground off to reveal the underlying phases, $\mathrm{Al}_{13} \mathrm{Fe}_{4}$ became the major phase (Figure 4d). The EDS concentration profile also corresponded to the $\mathrm{Al}_{13} \mathrm{Fe}_{4}$ phase around the ground 
off area (viz spots 19 and 20). The alloying elements such as $\mathrm{Mn}$ and $\mathrm{Si}$ tended to be present more around spots 21-25, apparently owing to the inward transportation of Al that expelled Mn and $\mathrm{Si}$.
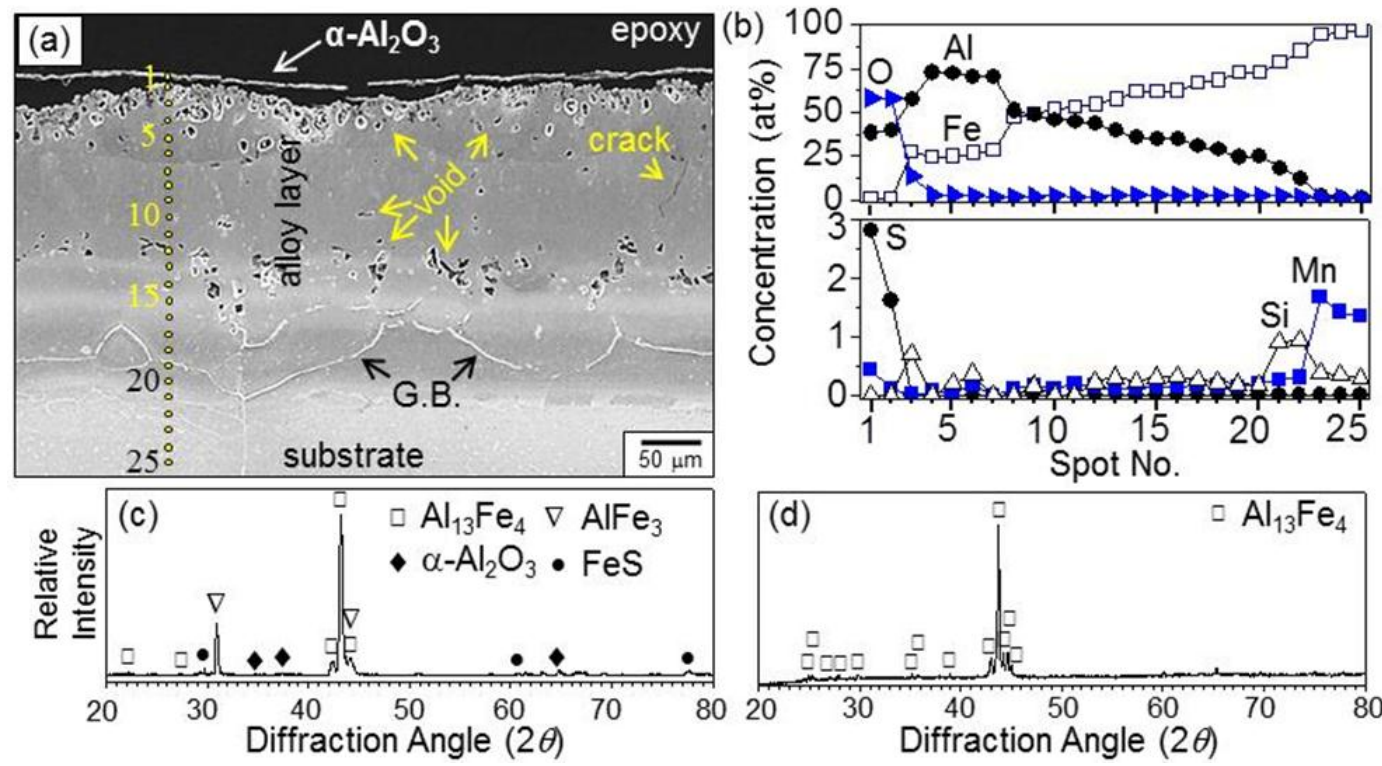

Figure 4. Al-hot dipped steel after corrosion in $\mathrm{N}_{2} / 0.1 \% \mathrm{H}_{2} \mathrm{~S}$ at $800{ }^{\circ} \mathrm{C}$ for $100 \mathrm{~h}$ : (a) etched cross-sectional SEM image; (b) concentration profiles of $\mathrm{Al}, \mathrm{Fe}, \mathrm{Mn}, \mathrm{Si}, \mathrm{S}$ and $\mathrm{O}$; (c) XRD pattern taken from the air-side; (d) XRD pattern after grinding off the upper part of the coating.

Figure 5 shows the microhardness profile of the $\mathrm{Al}$ hot-dipped carbon steel. Before heating, the microhardness ( $\mathrm{Hv}$ ) was about 65 for point 1 (viz $\mathrm{Al}$ topcoat), 859 for point 2 (viz $\mathrm{Al}_{3} \mathrm{Fe}$ ), 1020 for points 3-5 (viz $\mathrm{Al}_{5} \mathrm{Fe}_{2}$ in the alloy layer), and 223 for points 6-10 (viz $\alpha$-Fe substrate). Such hardness increment due to hot-dipping can improve the wear resistance and beneficially enhance the service life of the steel [6]. After heating at $800{ }^{\circ} \mathrm{C}$ for $100 \mathrm{~h}$, the microhardness of points 1 and 2 increased mainly due to oxidation or the incorporation of oxygen in the coating, whereas that of points 3-6 decreased mainly due to the counter-diffusion of $\mathrm{Al}$ and $\mathrm{Fe}$, which changed the brittle $\mathrm{Al}_{5} \mathrm{Fe}_{2}$-rich alloy layer to the ductile ( $\mathrm{AlFe}$ or $\mathrm{Al}_{13} \mathrm{Fe}_{4}$ )-rich alloy layer or another ductile Al-dissolved layer. Ductile AlFe and $\mathrm{Al}_{13} \mathrm{Fe}_{4}$ may be used as structural components because of their good oxidation- and corrosion-resistance, and high specific strength [5]. The microhardness of the substrate did not change noticeably before and after heating.

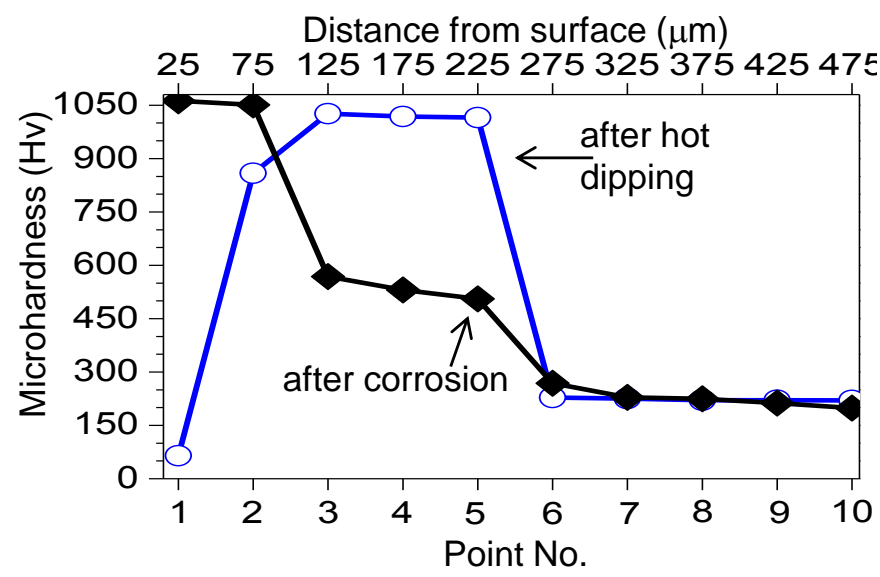

Figure 5. Microhardness variation along the depth of the Al hot-dipped carbon steel before and after heating at $800{ }^{\circ} \mathrm{C}$ for $100 \mathrm{~h}$ in $\mathrm{N}_{2} / 0.1 \% \mathrm{H}_{2} \mathrm{~S}$ gas. 
Figure 6 shows the Ellingham diagram (data from [10]). The oxides were more stable than the corresponding sulfides, whereas $\mathrm{Al}$ was more active than Fe. Hence, the most stable $\alpha-\mathrm{Al}_{2} \mathrm{O}_{3}$ formed preferentially upon exposure of the Al hot-dipped steel to $\mathrm{N}_{2} / 0.1 \% \mathrm{H}_{2} \mathrm{~S}$ mixed gas, and suppressed the corrosion significantly. By contrast, the uncoated steel degraded rapidly not by oxidation but by sulfidation. Upon exposure of the uncoated steel to $\mathrm{N}_{2} / 0.1 \% \mathrm{H}_{2} \mathrm{~S}$ mixed gas, $\mathrm{FeO}$ and $\mathrm{FeS}$ would form competitively. Since $\mathrm{FeS}$ is much more non-stoichiometric than $\mathrm{FeO}, \mathrm{FeS}$ overgrows $\mathrm{FeO}$ and covers the whole surface as the corrosion proceeds. The fast growth rate of FeS, incorporation of hydrogen and sulfur, void formation, and excessive stress that generated owing to the compositional difference in the scale resulted in the cracking and detachment of the FeS scale, allowing the direct contact of $\mathrm{N}_{2} / 0.1 \% \mathrm{H}_{2} \mathrm{~S}$ gas with the uncoated steel. This further accelerated the corrosion of the uncoated steel.

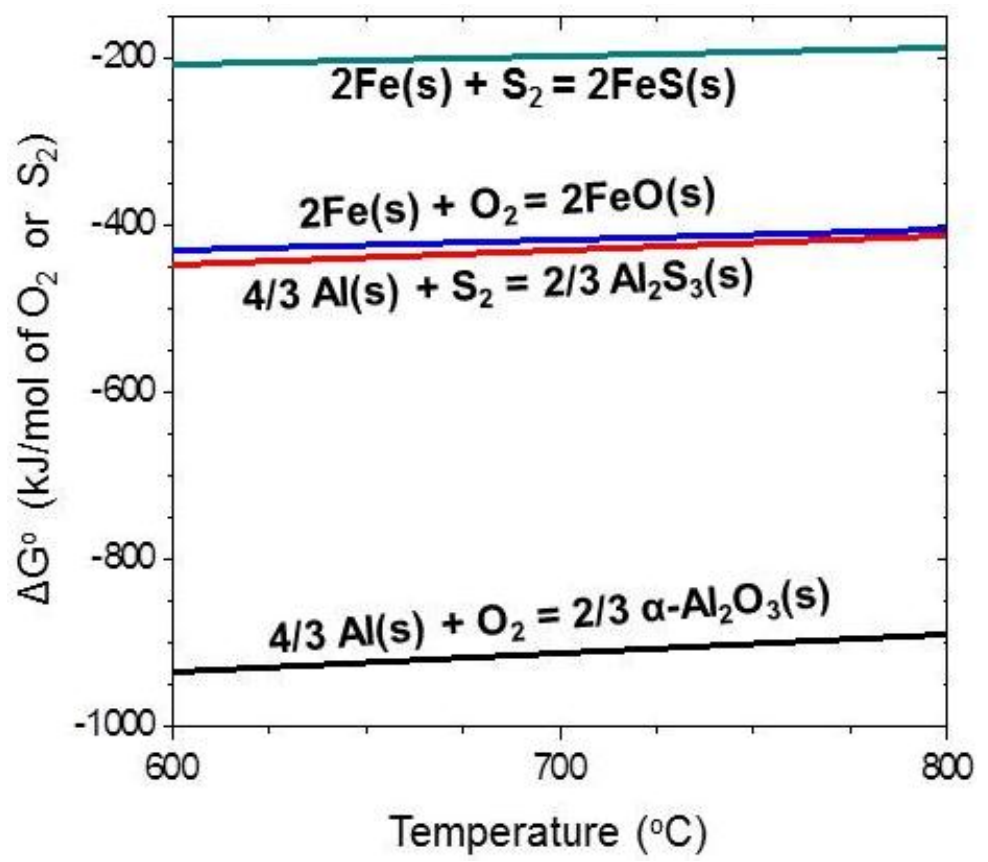

Figure 6. Ellingham diagram of oxides and sulfides that can form on the Al hot-dipped steel.

\section{Conclusions}

The carbon steel was hot-dipped in a molten $\mathrm{Al}$ bath, and corroded in $\mathrm{N}_{2} / 0.1 \% \mathrm{H}_{2} \mathrm{~S}$ mixed gas at $600-800{ }^{\circ} \mathrm{C}$ for up to $100 \mathrm{~h}$. The Al hot-dipping was found to be a good surface modification technique for the employed steel. The coating consisted primarily of the Al topcoat and an Al-Fe alloy layer firmly adhered on the steel substrate. The $\mathrm{Al}$ topcoat partially oxidized to the thin and non-adherent $\alpha-\mathrm{Al}_{2} \mathrm{O}_{3}$ scale from the surface. This effectively protected the carbon steel substrate. The formation of the $\alpha-\mathrm{Al}_{2} \mathrm{O}_{3}$ layer was highly preferred, because alumina grows quite slowly due to its high stoichiometry. Heating during the corrosion accompanied the counter-diffusion of $\mathrm{Al}$ and $\mathrm{Fe}$. This made the fingeror tongue-like morphology at the (Al-Fe alloy layer)/steel interface diffuse and dull, converted the Al-Fe intermetallic phases, changed the microhardness, and formed Kirkendall voids and cracks in the coating. In the case of uncoated carbon steel, thick, fragile, non-adherent FeS scales formed on the surface because hydrogen dissolved in the scales and non-protective sulfide scales formed.

Acknowledgments: This work was supported by the Korea Institute of Energy Technology Evaluation and Planning (KETEP) grant (No. 20143030050070) funded by the Korea government Ministry of Trade, Industry and Energy.

Author Contributions: Muhammad Ali Abro performed the experimental work, and drafted the paper. Dong Bok Lee supervised the experimental work, microstructural analyses, and finalized the paper.

Conflicts of Interest: The authors declare no conflict of interest. 


\section{References}

1. Mrowec, S.; Przybylski, K. Transport properties of sulfide scales and sulfidation of metals and alloys. Oxid. Met. 1985, 23, 107-139. [CrossRef]

2. Richards, R.; Jones, R.; Clements, P.; Clarke, H. Metallurgy of continuous hot dip aluminizing. Int. Mater. Rev. 1994, 39, 191-212. [CrossRef]

3. Bouayad, A.; Gerometta, C.; Belkebir, A.; Ambari, A. Kinetic interactions between solid iron and molten aluminium. Mater. Sci. Eng. A 2003, 363, 53-61. [CrossRef]

4. Deqing, W.; Ziyuan, S. Formation of $\mathrm{Al}_{2} \mathrm{O}_{3}$ layer on steel. J. Mater. Sci. Lett. 2003, 22, 1003-1006. [CrossRef]

5. Kobayashi, S.; Yakou, T. Control of intermetallic compound layers at interface between steel and aluminum by diffusion-treatment. Mater. Sci. Eng. A 2002, 338, 44-53. [CrossRef]

6. Van Trung, T.; Kim, M.J.; Bong, S.J. Characterization of microstructure, hardness and oxidation behavior of carbon steels hot dipped in Al and Al-1 at. \% Si molten baths. Korean J. Met. Mater. 2012, 50, 575-582.

7. Cheng, W.-J.; Wang, C.-J. Study of microstructure and phase evolution of hot-dipped aluminide mild steel during high-temperature diffusion using electron backscatter diffraction. Appl. Surf. Sci. 2011, 257, 4663-4668. [CrossRef]

8. Cheng, W.-J.; Wang, C.-J. Microstructural evolution of intermetallic layer in hot-dipped aluminide mild steel with silicon addition. Surf. Coat. Technol. 2011, 205, 4726-4731. [CrossRef]

9. Bouche, K.; Barbier, F.; Coulet, A. Intermetallic compound layer growth between solid iron and molten aluminium. Mater. Sci. Eng. A 1998, 249, 167-175. [CrossRef]

10. Barin, I. Thermochemical Data of Pure Substances; Wiley-VCH: Weihheim, Germany, 1989.

(C) 2016 by the authors; licensee MDPI, Basel, Switzerland. This article is an open access article distributed under the terms and conditions of the Creative Commons by Attribution (CC-BY) license (http:/ / creativecommons.org/licenses/by/4.0/). 